\title{
Radial to axillary nerve transfer
}

\author{
Vicente Vanaclocha, MD, PhD, ${ }^{1}$ Juan Manuel Herrera, MD, ${ }^{1}$ Marlon Rivera-Paz, MD, ${ }^{1}$ \\ Deborah Martínez-Gómez, MD, ${ }^{1}$ and Leyre Vanaclocha, BSc ${ }^{2}$
}

'Department of Neurosurgery, Hospital General Universitario de Valencia, Spain; and

${ }^{2}$ Medical School, University College London, United Kingdom

Axillary nerve injury is common after brachial plexus injuries, particularly with shoulder luxation. Nerve grafting is the traditional procedure for postganglionic injuries. Nerve transfer is emerging as a viable option particularly in late referrals. At the proximal arm the radial and axillary nerves lie close by. Sacrificing one of the triceps muscle nerve branches induces little negative consequences. Transferring the long head of the triceps nerve branch is a good option to recover axillary nerve function. The surgical technique is presented in a video, stressing the steps to achieve a successful result.

The video can be found here: https://youtu.be/WbVbpMuPxIE.

KEYWORDS radial nerve; axillary nerve; radial to axillary nerve transfer; nerve trauma; video 